\title{
InTELligence Failure as a Mutually Reinforcing Politico-InTElligence Dynamic: THE CHILCOT REPORT AND THE NATURE OF THE IRAQ WMD INTELLIGENCE FAILURE
}

\section{By MARK PHYTHIAN*}

By the time the Chilcot Report was published in July 2016, inquiries of one sort or another focusing on Iraq had been a semi-permanent feature of British politics for a quarter of a century. These stretched back to the aftermath of the 1991 Gulf War and the House of Commons Trade and Industry Select Committee's investigation of Britain's role in producing a 'supergun' for Saddam Hussein's regime, and included Sir Richard Scott's 1992-96 investigation into the export of defence and dual-use goods to Iraq. ${ }^{1}$ The question of intelligence failure in relation to the 2003 invasion of Iraq had itself been either the context for or subject of four previous inquiries by the time the Chilcot inquiry was established. The Foreign Affairs Committee (FAC) quickly published a report into The Decision to Go to War in Iraq in July $2003,{ }^{2}$ but without access to intelligence assessments. The parliamentary Intelligence and Security Committee (ISC) produced its report on Iraqi Weapons of Mass Destruction Intelligence and Assessments in September 2003. ${ }^{3}$ This was followed by the report of a judicial inquiry conducted by a former Lord Chief Justice of Northern Ireland, Lord Hutton, to investigate the circumstances surrounding the death of Dr David Kelly, a Ministry of Defence biological weapons expert who committed suicide after giving evidence to the FAC inquiry. ${ }^{4}$ After this report in January 2004, the Blair Government felt obliged to concede a further inquiry into the WMD question, to be conducted by a team of privy counsellors led by former Cabinet Secretary Lord Butler and including former Northern Ireland Permanent Secretary Sir John Chilcot among its members.

The resulting report ('Butler Report') provided the most detailed analysis of intelligence on Iraq's WMD of any of these inquiries, and included extracts from Joint Intelligence Committee (JIC) assessments on Iraq. ${ }^{5}$ These were presented alongside extracts from Iraq's Weapons of Mass Destruction: The Assessment of the British Government, the September 2002 dossier that, in light of growing public debate and concern, the Blair government produced to make the case for war in Iraq, and alongside the Foreword to this published in Tony Blair's name. This enabled the Butler Report to demonstrate two things: first, that the dossier production process impacted on intelligence, both on what was collected and how it was treated; second, that the claims made in the Foreword to the dossier were in advance of anything that could be supported by the intelligence base. Given that the issue had already been covered so thoroughly, particularly by Butler, what could Chilcot add to our understanding of intelligence failure in general, and of the Iraq WMD intelligence failure in particular?

\footnotetext{
* Professor, Politics and International Relations, University of Leicester. Email: mp249@leicester.ac.uk. All URLs are correct as of [date of submission for final type-setting]. I would like to thank the editors for their helpful comments on an earlier draft of this article.

${ }^{1}$ Report of the Inquiry into the Export of Defence Equipment and Dual-Use Goods to Iraq and Related Prosecutions (HMSO 1996).

${ }^{2}$ House of Commons Foreign Affairs Committee, The Decision to go to War in Iraq: $9^{\text {th }}$ Report of Session 2002-3 (Cm 6123, 2004).

${ }^{3}$ Intelligence and Security Committee, Iraqi Weapons of Mass Destruction - Intelligence and Assessments, (Cm 5972, 2003).

${ }^{4}$ Lord Hutton, Report of the Inquiry into the Circumstances Surrounding the Death of Dr David Kelly CMG, 28 January 2004 (HC 247).

${ }^{5}$ Review of Intelligence on Weapons of Mass Destruction (Report of a Committee of Privy Counsellors), 14 July 2004 (HC 898).
} 


\section{THE CONTRIBUTION OF THE CHILCOT REPORT}

My argument here is that the Chilcot Report's contribution is twofold. First, it is to be found in the unprecedented detail contained in the Report and provided in oral evidence sessions and written submissions which were published on the Inquiry's website. The earlier Butler review took evidence from approximately 50 witnesses, but this was not published. Moreover, the Butler Report was much briefer than the Chilcot Report, at just over 200 pages, and had a broader remit than just the case of Iraq, also covering intelligence on WMD relating to North Korea, Iran, Libya and the A. Q. Khan nuclear network. ${ }^{6}$ It also worked to a much tighter timescale. ${ }^{7}$ While the Butler Report (and earlier Hutton report) had covered the process by which the September dossier came to be written, Chilcot takes us much further in demonstrating in detail how in-coming intelligence during this period was received, analysed, and disseminated, and how it impacted on the dossier and subsequent characterisations of the Iraq WMD picture from September 2002 to the initiation of war in March 2003. Moreover, the timescale imposed on the Butler review meant that key pieces of evidence-for example, the report of the US Iraq Survey Group and official acceptance that some human intelligence reporting was unreliable, so leading to its formal withdrawal-only emerged after the Butler review had concluded its work. ${ }^{8}$

Second, the Chilcot Report contributes to understandings of the phenomenon of intelligence failure in conceptual terms. There are a number of ways of approaching this issue. ${ }^{9}$ One is to seek to locate failure at a point in the intelligence cycle (the model held to describe the intelligence process and usually said to comprise five stages: direction; collection; processing; analysis; and dissemination). While clearly useful, one weakness of this approach is that it can encourage the idea that intelligence failure is to be located at a single point in the cycle (for example, in collection or in analysis). Another is that the model rests on the flawed assumption that these are, in practice, sequential processes rather than overlapping and at times concurrent ones. ${ }^{10} \mathrm{In}$ a seminal article on the nature of intelligence failure published in 1978, Richard Betts was more specific, and argued that:

In the best-known cases of intelligence failure, the most crucial mistakes have seldom been made by collectors of raw information, occasionally by professionals who produce finished analyses, but most often by the decision makers who consume the products of intelligence services. Policy premises constrict perception, and administrative workloads constrain reflection. Intelligence failure is political and psychological more often than organizational. ${ }^{11}$

\footnotetext{
${ }^{6}$ The Chilcot Report was published in 12 volumes containing 2.6 million words. I am not suggesting a direct comparison as the remits of each differed. Nevertheless, the scale of the Chilcot Inquiry was of a different order to that of Butler.

${ }^{7}$ Established in early February 2004, it was required to report before the summer recess, which it did on 14 July 2004.

${ }^{8}$ Terms of reference and timescale can be seen as two of the tools governments have at their disposal in attempting to limit political fall-out from commissions of inquiry. See S Farson and M Phythian (eds), Commissions of Inquiry and National Security: Comparative Approaches (Praeger Security International 2011).

${ }^{9}$ For a detailed discussion, see EJ Dahl, Intelligence and Surprise Attack: Failure and Success from Pearl

Harbor to 9/11 and Beyond (Georgetown University Press 2013) 6-26.

${ }^{10}$ See the discussion and alternative conceptualisations in M Phythian (ed), Understanding the Intelligence Cycle (Routledge 2013).

${ }^{11}$ RK Betts, 'Analysis, War, and Decision: Why Intelligence Failures are Inevitable' (1978) 31 World Politics 61.
} 
This argument directed attention towards the interface between the worlds of intelligence and policy, and suggested that responsibility for the most significant failures lay not with intelligence but in the political realm. This approach also hints at other ways of thinking about intelligence. One is to distinguish between intelligence and policy failure-between a failure to collect and correctly analyse intelligence and a failure to heed it. Stalin's discounting of intelligence indicating German plans to invade the Soviet Union in 1941 following the signing of the 1939 Molotov-Ribbentrop Pact is a classic example, but this distinction has also been used to explain, for example, the failure to anticipate the Argentine invasion of the Falkland Islands in 1982. ${ }^{12}$ This approach and that of Betts hint at another way of thinking about intelligence failure, in terms of what has been termed 'politicization'. This refers to the application of political pressure and the way in which this impacts on the intelligence process. This is without doubt a very useful approach, but does suffer from perceptions that it is 'poorly defined, conceptualized and operationalized.' ${ }^{13}$ There is no doubt that the concept can seem somewhat amorphous at times and would benefit from greater definitional clarity. To this end, Gregory Treverton has proposed a typology of five different forms of politicization, ranging from 'hard' to 'soft' forms, from direct pressure at the hard end to question asking and shared mindset at the soft end. ${ }^{14}$ One problem facing anything approaching a clinical diagnosis of politicization is rooted in the fact that more flagrant attempts via direct pressure are relatively rare, and that the phenomenon is most often perceived in its softer variants, where the diagnosis can be contested. For example, politicians can view repeated 'question asking' as being entirely legitimate. Rather than diagnose failure rooted in 'shared mindset' as being a symptom of politicization, post mortem inquiries have been more likely to take the safer route of diagnosing 'Groupthink' which, because it arises out of a group dynamic, precludes the need to identify individual responsibility. Yet another approach to intelligence failure involves focusing on structural explanations for failure and locating failure in the nature of intelligence organisations and processes, for example in inadequate sharing, challenging, or review of intelligence. ${ }^{15}$ Similarly, bureaucratic politics provides a useful approach to understanding aspects of intelligence behaviour in organisational terms. ${ }^{16}$

The Chilcot Report's detailed narrative reconstruction style does not extend to explicit reflection about conceptual approaches, nor to detailed commentary on the conclusions of the previous inquiries into Iraq WMD intelligence. The conceptual implications need to be inferred from the detailed evidence presented in the Report. On this basis, I would argue that a key contribution of the Chilcot Report is to demonstrate that a sole focus on any one of the approaches outlined above - the intelligence cycle, structural explanations, politicization, or an intelligence-policy dichotomy - cannot fully capture the dynamic and complex nature of intelligence failure in this case. The Chilcot Report presents the particular case of Iraqi WMD as a failure that was multi- rather than mono-causal, and dependent on a mutually reinforcing politico-intelligence dynamic. Structural explanations certainly have a place in this. Had challenge and review been effectively built into the intelligence system, the Iraq WMD

\footnotetext{
${ }^{12}$ See, for example, L Freedman, The Official History of the Falklands Campaign Volume 1: The Origins of the Falklands War (Routledge 2005) 216-27. Freedman was a member of the Chilcot Inquiry Committee.

${ }^{13}$ S Marrin, 'Rethinking Analytic Politicization' (2013) 28 Intelligence and National Security 32-54.

${ }^{14}$ GF Treverton, 'Intelligence Analysis: Between "Politicization" and Irrelevance' in RZ George and JB Bruce (eds), Analyzing Intelligence: Origins, Obstacles, and Innovations (Georgetown University Press 2008).

${ }^{15}$ For example, AB Zegart, Flawed by Design: The Evolution of the CIA, JCS, and NSC (Stanford UP 1999) and Spying Blind: The CIA, the FBI and the Origins of 9/11 (Princeton UP 2007).

${ }^{16}$ Classic statements of this approach include MH Halperin, 'Why Bureaucrats Play Games' (1971) 1 Foreign Policy 70; GT Allison and MH Halperin, 'Bureaucratic Politics: A Paradigm and Some Policy Implications' (1972) 24 World Politics 40.
} 
failure is unlikely to have occurred in the manner or on the scale that it did. However, structural explanations alone cannot capture the politico-intelligence dynamic that was core to the failure here. This was a consequence of intelligence being drawn into advocacy of war via its involvement in construction of the September 2002 Iraq dossier.

The Chilcot Report's empirical and conceptual contributions combine to enable the reader to understand this failure as stretching across three distinct phases: first, regarding the impact of the decision to produce the September 2002 dossier; second, the failure to challenge the intelligence underpinning the dossier and mindsets this shaped in the period from September 2002 to the invasion of Iraq in March 2003; and finally, the post-war response to the increasingly inescapable reality that intelligence had failed when the WMD that had constituted the British government's formal casus belli turned out not to exist. This article now goes on to consider how the Chilcot Report contributes to our understanding of each of these phases in turn.

\section{Phase ONE: INTELLIGENCE AND THE SEPTEMBER 2002 DOSSIER}

Iraq had proved a hard target for western intelligence after the 1991 Gulf War. Under UN Security Council Resolution 687, passed in the aftermath of the war, Iraq was required to destroy its WMD under international supervision. Yet Iraq adopted a policy of obstructing the UN weapons inspectors of UNSCOM, the UN Special Commission responsible for overseeing and verifying this destruction, giving rise to the widespread assumption that Iraq was engaged in a strategy of retaining, and concealing, a WMD capability. This general belief was reinforced by the revelation that Iraq's nuclear weapons programme was more advanced than had been believed prior to the war.

The Chilcot Report characterises what developed after 1991 in this context as an 'ingrained belief that Saddam Hussein's regime retained chemical and biological warfare capabilities, was determined to preserve and if possible enhance its capabilities, including at some point in the future a nuclear capability, and was pursuing an active policy of deception and concealment'. ${ }^{17}$ The Report found that while, over time, 'the detail of individual JIC Assessments on Iraq varied, this core construct remained in place'. ${ }^{18}$ The already difficult job of gathering intelligence on Iraq became even more challenging after the withdrawal of the UNSCOM team in advance of the 1998 Desert Fox attacks by the US and UK. In this context, as the Chilcot Report puts it: 'The view conveyed in JIC Assessments between December 2000 and March 2002 was that, despite the considerable achievements of UNSCOM ... the inspectors had been unable to account for some of the ballistic missiles and chemical and biological weapons and material'. ${ }^{19}$ These were assumed to have been successfully hidden. Perhaps even more problematically, Iraq retained the knowledge base that would enable it to reconstitute its WMD programmes in the future. Nevertheless, overall the strategy of containment of Iraq was held to be working. Iraq was viewed by the JIC as representing less of a threat than Iran, Libya and North Korea, each of which had nuclear programmes, whereas Iraq's nuclear facilities had been dismantled by UNSCOM. At the same time, the JIC judged that Iraq was unlikely to give non-conventional weapons to terrorists.

\footnotetext{
${ }^{17}$ The Report of the Iraq Inquiry (Report of a Committee of Privy Counsellors), Executive Summary (ES), para 496. All sections of the Report are available at $<$ http://www.iraqinquiry.org.uk/the-report/>. Many of the direct quotations cited here from the Report are in fact quoted by the Report from other sources; for full details of these other sources see the relevant paragraphs of the Report.

${ }^{18}$ Report, ES, para 497.

${ }^{19}$ Ibid, para 501.
} 
The 11 September 2001 terrorist attacks, however, transformed threat perceptions. The JIC felt that the attacks 'set a new benchmark for terrorist atrocity. The level of destruction and the public impact are unprecedented.' The JIC warned that terrorists " "seeking comparable impact may try to use chemical, biological radiological or nuclear devices". ${ }^{20}$ Containment of Iraq, therefore, came to be viewed as involving greater risk. On 26 February 2002, Sir Richard Dearlove, then Chief of the Secret Intelligence Service (SIS), reported that the Bush Administration was abandoning containment and developing plans for a military campaign against Iraq to be preceded by an ultimatum for the return of weapons inspectors that set the bar "so high that Saddam Hussein would be unable to comply". ${ }^{21}$ The Chilcot Report notes that Prime Minister Tony Blair and Foreign Secretary Jack Straw then began publicly making the case that Iraq posed a threat which had to be dealt with. However, Chilcot also notes that this 'was not the result of a step change in Iraq's capabilities or intentions'. ${ }^{22}$

The Chilcot Report fixes the origin of the September dossier in this period. Initially, the government wanted a paper that would inform the public about the dangers of WMD proliferation, focusing on North Korea, Iran, Libya and Iraq, to coincide with Blair's April 2002 visit to President Bush in Texas. On seeing a draft of this paper on 8 March 2002, Straw commented: 'Good, but should not Iraq be first and also have more text? The paper has to show why there is an exceptional threat from Iraq. It does not quite do this yet. ${ }^{23}$ As noted above, intelligence did not demonstrate that Iraq was an exceptional threat. Nevertheless, later that month Straw determined that a paper on Iraq alone should be produced. Just four days later, on 22 March, he was informed that the 'evidence would not convince public opinion that there was an imminent threat from Iraq,' and the publication plan was shelved. ${ }^{24}$

The Chilcot Report shows how making the public case for an Iraqi threat did impact on perceptions in that such statements 'about Iraq's proscribed activities and the potential threat they posed were understandably written in more direct and less nuanced language than the JIC Assessments on which they drew. ${ }^{, 25}$ A tendency to talk in terms of Iraq's 'weapons of mass destruction' without distinguishing between them, or the circumstances in which it was thought the different types might possibly be used, compounded this effect. This tendency was, the Chilcot Report says, "likely to have created the impression that Iraq posed a greater threat than the detailed JIC Assessments would have supported. ${ }^{26}$ But this more strident talk heightened public concern which led, in turn, to the revival of the idea of publishing an account of the threat, a decision formally announced by Tony Blair on 3 September 2002.

In a memo of 4 September 2002, the FCO's John Williams cautioned that the 'evidence dossier' was 'unlikely to be enough by itself to win the argument: it will convince persuadable opinion only if launched in the right environment, framed by a broad case that establishes Iraq as a threat to international peace and security.' Crucially, he warned that there was "no "killer fact" in the dossier which "proves" that Saddam must be taken on now, or this or that weapon will be used against us'. ${ }^{27}$ This was the background to the invitation to SIS to contribute material to the dossier, and the decision that overall responsibility for the

\footnotetext{
${ }^{20}$ Report, vol 4, Section 4.1, para 127.

${ }^{21}$ Report, ES, para 68.

${ }^{22}$ Ibid, para 508.

${ }^{23}$ Ibid, para 509 (emphasis in original).

${ }^{24}$ Ibid, para 511.

${ }^{25}$ Ibid, para 513.

${ }^{26}$ Ibid, para 518.

${ }^{27}$ Report, vol 4, Section 4.2, para 192.
} 
dossier's production should lie with John Scarlett, Chairman of the JIC, hence conferring the authority of the JIC on the contents of the dossier. These decisions would have serious consequences for the collection, analysis and dissemination of intelligence on Iraq's WMD programmes and give rise to a pronounced disinclination to review this intelligence. In parallel, the public case for the threat posed by Iraq continued to be made. At a press conference at Camp David on 7 September, Blair spoke of how 'the threat from Saddam Hussein and weapons of mass destruction, chemical, biological, potentially nuclear weapons capability, that threat is real...' ${ }^{28}$ On 9 September the JIC issued an 'Assessment' of Iraq's chemical and biological weapons capabilities that represented a hardening of previous judgements. The tone of this Assessment, the Butler Report had noted, was set by its first 'Key Judgement': 'Iraq has a chemical and biological weapons capability and Saddam is prepared to use it.' The Butler Report had also commented that it was 'struck by the relative thinness of the intelligence base supporting the greater firmness of the JIC's judgements on Iraqi production and possession of chemical and biological weapons, especially the inferential nature of much of it'. ${ }^{29}$

Nevertheless, John Scarlett drew on this Assessment in producing a draft of the dossier on 10 September, including the claim that Iraq could deploy chemical and biological weapons within 45 minutes of an order being issued. On a visit to Washington on 12 September, Scarlett briefed Bush Administration officials on the dossier plan and, according to Ambassador Sir Christopher Meyer, their advice was

not to get trapped into juridical standards of proof. The bulk of the case should rest on history and common-sense argument, rather than specific new intelligence. When it came to Saddam's WMD, absence of evidence was not the same as evidence of absence. We should not be afraid to argue that, just as in 1991, Iraq's programmes were probably much further advanced than we knew. ${ }^{30}$

There were two key pieces of in-coming intelligence in this period, only one of which arrived in time to influence the dossier. This was an 11 September SIS report drawing on reporting from a new source stating that Iraq had accelerated the production of chemical and biological agents and built additional facilities throughout Iraq, and that Saddam 'was determined to maintain his CBW capability'. ${ }^{31}$ In support of this, the report related the source's observation that:

New accommodation for senior scientists and their colleagues was being built near to the major BW and CW production sites. The families of those scientists would, in effect, be held hostage. They would be discouraged from deserting or from leaking information about activities at their facilities that might lead to the sites being targeted for bombing by allied forces. ${ }^{32}$

SIS was not in direct contact with this new source (who was a sub-source-a source of a source), although this fact was not made clear in the SIS report. ${ }^{33}$ Given the significance of the reporting and the belief that the source would be able to deliver further material, the 11 September report was sent to only a very limited number of people approved by Sir Richard Dearlove. ${ }^{34}$ As the Chilcot Report records:

\footnotetext{
${ }^{28}$ Ibid, para 229.

${ }^{29}$ Ibid, para 261.

${ }^{30}$ Ibid, para 400.

${ }^{31}$ Ibid, para 403.

32 Ibid, para 413.

${ }^{33}$ Ibid, para 406.

34 Ibid, paras 416-18.
} 
Notes of a telephone discussion between Sir Richard Dearlove and Mr Scarlett on 11 September recorded that Sir Richard told Mr Scarlett:

- SIS was 'on the edge of [a] significant intel breakthrough'. The intelligence was from a 'first contact with BCW phenomenal access'. It could be the 'key to unlock' Iraq's BCW programme.

- Asked whether the source definitely had 'the access', Sir Richard replied 'yes'.

- Sir Richard expected 'additional material in 3-4 weeks time'. He mentioned a 'CD with everything in it'. 35

The following day, Dearlove and an SIS colleague briefed Tony Blair on this new intelligence, a move which some witnesses to the Chilcot Inquiry criticised as being 'precipitate'. ${ }^{36}$

This SIS report of 11 September was used by John Scarlett in determining two Key Judgements to be included in the September dossier: that Iraq had 'continued to produce chemical and biological agents' and that it had 'military plans for the use of chemical and biological weapons' ${ }^{37}$ Moreover, the Chilcot Report found that the 'judgements on Iraq's production of chemical and biological weapons and the circumstances in which they could be used became the baseline for subsequent advice to Ministers and public statements on the threat posed by Iraq'. ${ }^{38}$ In giving evidence, Dearlove told the Inquiry that the 11 September SIS report had not been used in the production of the dossier. ${ }^{39}$ However, Scarlett's recollection was that the report was 'influential' and 'did famously influence what was said in the dossier. ${ }^{40}$

One group that was excluded from the circulation of the 11 September SIS report was those chemical and biological weapons experts in the Defence Intelligence Staff (DIS) who might have been best placed to challenge it. When they saw a draft of the dossier they raised questions about the wisdom of some of the claims made in the Foreword, published in the name of the Prime Minister, and in the main body. For example, a chemical warfare expert raised concerns with the DIS Director of Science and Technology. One related to the statement in the Foreword that Blair believed that the 'assessed intelligence has established beyond doubt' that 'Saddam has continued to produce chemical and biological weapons', a statement that could not reasonably have been included absent the 11 September SIS report. The DIS expert recognised that Blair was "expressing his own "belief" about what the assessed intelligence has established,' but nevertheless maintained that 'based on the intelligence available to me it has NOT established beyond doubt that Saddam has continued to produce chemical [and biological] weapons. ${ }^{41}$ Another concern raised by the DIS expert related to the judgement, included in paragraph 6 of the Executive Summary of the dossier, that Iraq had 'continued to produce chemical and biological agents'. This was a stronger statement than the DIS expert felt the intelligence warranted. ${ }^{42}$

A second SIS report, dated 23 September, added to the picture of a step-change in the level of threat posed by Iraq suggested by the 11 September report. The 23 September report came from the same sourcing chain as the 11 September report. It stated that VX, sarin and soman had been produced at the $\mathrm{Al}$ Yarmuk facility and had been observed being loaded into a range of 'containers,' including 'linked hollow glass spheres'. The source also provided information on 'accelerated production of $\mathrm{CW}$ substances at Al-Yarmuk for several years'.

\footnotetext{
35 Ibid, para 408.

${ }^{36}$ Ibid, para 429.

${ }^{37}$ Ibid, para 432.

${ }^{38}$ Ibid, para 433.

${ }^{39}$ Ibid, para 437.

${ }^{40}$ Ibid, para 440.

${ }^{41}$ Ibid, para 609.

42 Ibid, para 611.
} 
For SIS this was consistent with the earlier reporting and was considered 'valuable intelligence'. ${ }^{43}$ Once again, the value of the intelligence and potential for further reporting meant that circulation of the 23 September report was restricted to the same group that had received the previous report. The information arrived too late to go into the dossier but nevertheless reinforced confidence in the dossier's contents and underlying analysis.

The Butler Report had been critical of the decision to not circulate the 11 September report to the experts in the DIS. While recognising the concerns Sir Richard Dearlove legitimately held about source protection, the Chilcot Report shared

the conclusion of the Butler Review that [the 11 September report] should have been shown to the experts in the Defence Intelligence Staff who could have commented on the credibility and validity of that report and the subsequent report issued on 23 September and advised their senior managers and the Assessments Staff. ${ }^{44}$

The Chilcot Report also agreed with the Butler Report that the dossier 'contained a stronger assessment in relation to Iraqi chemical weapons production than was justified by the available intelligence', and found that the 11 September report 'was a factor in that'. ${ }^{45}$ The Chilcot Report added that 'Sir Richard Dearlove's personal intervention, and its urgency, gave added weight to a report that had not been properly evaluated and would have coloured the perception of Ministers and senior officials. The report should have been treated with caution. ${ }^{46}$

Witness SIS1 told the inquiry that he thought the confidence placed in the SIS reports of 11 and 23 September 'was based in part on wishful thinking ... SIS was under quite extraordinary pressure to try and get a better view of Iraq's WMD programme, and I think we marketed that intelligence ... before it was fully validated. ${ }^{47}$ The Chilcot Inquiry team asked SIS1whether there were doubts in SIS's 'collective consciousness' about this intelligence before March 2003. SIS1 replied: 'Well before that. Even while it was still going on. Here was a chap who promised the crock of gold at the end of the rainbow. Now, you have got to go for those, because sometimes that can be just what you are looking for. ${ }^{48}$ Witness SIS3 was asked for his conclusions after reviewing the case in 2004, and replied:

Well, I think it illustrated, first of all, the dangers of a chain of sourcing ... The second point is that when you have senior people who reach down into the machinery and try moving the cogs, if I may put it like that ... you obviously disenfranchise the operational chain of command. You cut out expertise, and perhaps you also disable that element of challenge which is, I think, a very important part of operational life in the Service.

SIS3 also agreed with the proposition put forward by Sir David Omand in evidence to the Inquiry that SIS had 'overpromised and underdelivered.' ${ }^{49}$ When asked by the Inquiry about the sense of political pressure he had alluded to, SIS3 replied:

Well, it was obviously pressure-whether you describe it as political pressure or merely pressure from Assessments Staff - to have more material, in a sense responding to the tasking that we had received. Clearly when you are under a lot of pressure to produce intelligence, there is a risk that you will take short cuts. ${ }^{50}$

\footnotetext{
${ }^{43}$ Ibid, para 441.

${ }^{44}$ Ibid, para 656.

${ }^{45}$ Ibid, paras 653-54.

${ }^{46}$ Ibid, para 657.

${ }^{47}$ Report, vol 4, Section 4.3, para 567.

${ }^{48}$ Ibid, para 568.

${ }^{49}$ Ibid, para 578 (ellipses in original).

${ }^{50}$ Ibid, para 580.
} 
Another form of short-cut was the failure to revisit the core assumption after September 2002. At no stage was the hypothesis that Iraq might not have chemical or biological weapons or programmes considered by either the JIC or the policy community. The core construct remained intact. The Chilcot Report is clear that the SIS reports of 11 and 23 September were significant in this, as they provided further confirmation of what was widely understood to be the case: that Iraq aimed to develop a WMD capability; that over the years it had mastered the art and science of denial and deception; and, as John Scarlett had been reminded by the Bush Administration, that absence of evidence could not be considered to constitute evidence of absence. The SIS reports became an important element in framing the debate and options over Iraq from September 2002 to the outbreak of war in March 2003.

However, the weakness of the reporting chain was not made clear to ministers when informing them of the intelligence from the source. The Chilcot Report indicates that when Dearlove briefed Foreign Secretary Straw on 27 September about the new source and the anticipated future intelligence windfall, Straw 'asked several questions about [codename's] motivation and whether he was genuine'. Sir Richard told Straw that the answers were 'money and ideology,' and 'yes', respectively. ${ }^{51}$ By early October, though, questions were emerging within SIS about the intelligence provided by the source, particularly the reference in the 23 September report to glass containers being used in the transportation of chemical munitions. This was unusual and within SIS seemed reminiscent of the off-beam depiction of VX nerve agent being transported in glass containers in the 1996 Hollywood action film The Rock. ${ }^{52}$ Also, as time went on in an environment where the international community in general remained to be convinced of the necessity of going to war to disarm Iraq, the additional material promised from this source took on a growing significance but still did not materialise. An 11 November 2002 document described this issue as 'reaching a crucial point' and being afforded SIS's 'highest priority', with Dearlove said to be 'following progress of the case' personally. ${ }^{53}$ There is evidence of some scepticism in SIS by 6 December as to whether there would be any further reporting from this source, and the suggestion that a 'health warning' should therefore be attached to information already sent. ${ }^{54}$ A 9 December SIS document flagged up concerns about the source and raised the possibility that he had 'made up all or part of the account of his dealings' with his own source (the subsource). A further report was less pessimistic and may have reduced concerns about the reliability of the source.

This nascent debate was not taking place in a vacuum. It coincided with the entry into Iraq of the United Nations Monitoring, Verification and Inspection Commission (UNMOVIC) to monitor and verify compliance with Iraq's disarmament requirements under UN Security Council Resolution 1441 of 8 November 2002. In this context, the SIS source could be vital in demonstrating that Iraq continued to conceal WMD. On 19 December Straw asked Dearlove for an 'update on the likelihood' of the source 'producing silver bullet intelligence to guide the UNMOVIC inspection teams. ${ }^{55}$ Now Dearlove was more equivocal than previously, telling Straw that 'the outcome of [codename] was still in the balance'. SIS was looking into the matter. The sub-source 'definitely existed', but 'may not have written up

\footnotetext{
${ }^{51}$ Ibid, para 128.

52 Ibid, paras 130-31.

${ }^{53}$ Ibid, para 132.

${ }^{54}$ Ibid, para 134.

55 Ibid, para 137.
} 
the intelligence in the manner which was being claimed for him,' Dearlove reported. ${ }^{56}$ This was not what Straw wanted to hear. Straw was concerned about 'what would happen without evidence of a clear material breach' as the Prime Minister 'had made the point that unless there was a clear material breach, he would face political difficulties in joining the US in military action'. It was 'important that there was a sufficiently strong case against Saddam to move a resolution at the UNSC' in order to "scare the pants off the Iraqis". 57

These passages of the Chilcot Report show how the environment of political pressure under which intelligence laboured did not cease with the deadline for production of the September dossier. If anything, pressure intensified in the months that followed, making it difficult in bureaucratic terms for intelligence to row back on the apparent promises of September without risking institutional damage. Meanwhile, when Iraq produced a weapons declaration on 7 December, the JIC understood this, in part, in terms of how fully it addressed the points raised in the September dossier, even though the reliability of a key source for that intelligence was now in question.

Witness SIS1 briefed Prime Minister Blair in early January 2013 on the intelligence picture, telling him that the evidence was 'highly damning' but did not contain a 'silver bullet'. ${ }^{58}$ Blair was clear that he needed evidence that Iraq was in breach of Resolution 1441. This would impact on international opposition and possibly ease the path to a second UN Security Council Resolution explicitly sanctioning war. SIS1 told the Chilcot Inquiry that this environment did not amount to 'unusual pressure', but recognised that intelligence could hold the key to whether Britain was able to participate in the war to which the US was already committed. ${ }^{59}$

The Chilcot Report cites a meeting between Blair and Sir Richard Dearlove on 9 January 2003 in which: 'In response to a question from Mr Blair about the likelihood of being able to find a "silver bullet" that would demonstrate a material breach', Sir Richard reportedly said that "he felt the odds were 50/50". That was "higher than the US estimates but he simply could not guarantee a successful outcome". 60 Blair's parting words to Dearlove were: 'Richard, my fate is in your hands. ${ }^{\text {'61 }}$ The failure of UNMOVIC to identify this material breach did nothing to encourage a reassessment of the core assumption that Iraq continued to conceal WMD.

On 30 January 2003, JIC Chairman Scarlett reflected on how odd it was that with UNMOVIC present the Iraqi regime did not appear 'to be worried about the obvious risk of leaks from the thousands of people aware of this concealment activity'. This could have set off alarm bells, but instead Scarlett attributed this apparent Iraqi insouciance to the 'brutal discipline' of the regime. ${ }^{62}$ Scarlett wrote that he continued

to be struck by the regime's ability to conduct complex surveillance and deception operations without unforced errors or major slip ups. Co-ordinating the dispersal of materials and associated documentation around the country and fielding surprise UNMOVIC and IAEA visits to hundreds of sites in a few weeks is a complex undertaking and evidence of the regime's continuing grip on the population at least of central Iraq. ${ }^{63}$

\footnotetext{
${ }^{56}$ Ibid, para 138.

${ }^{57}$ Ibid, para 140 .

${ }^{58}$ Ibid, para 167.

${ }^{59}$ Ibid, para 168-69.

${ }^{60}$ Ibid, para 177.

${ }^{61}$ Ibid, para 178.

${ }^{62}$ Ibid, para 677.

${ }^{63}$ Ibid, para 678.
} 
When Witness SIS1 was asked by the Inquiry whether the intelligence on Saddam Hussein's strategy for dealing with inspections reinforced preconceptions about Iraqi concealment, he replied:

I think they looked guilty as hell ... there was quite a lot of evidence of the unco-operative and mule-headed and crude efforts to make the inspectors' life more difficult ... Yes, and it seemed to form part of a consistent picture, allowing for the fact that there was a certain assumption in the first place about what that picture was. ${ }^{64}$

After its 9 September 2002 Assessment, the JIC was not asked to review its judgements on Iraq's capabilities and programmes. Nor did the JIC itself suggest such a review. The Chilcot Report is highly critical of this failure, finding that:

Given the weight which rested on the JIC's judgements about Iraq's possession of WMD and its future intent for the decision in March that military action should, if necessary, be taken to disarm Iraq, a formal reassessment of the JIC's judgements should have taken place. ${ }^{65}$

One conclusion that might be drawn from this failure to re-examine bedrock assumptions is that experienced intelligence professionals did not feel that the environment created by politicians was conducive to raising the possibility of an alternative hypothesisi.e. that Iraq did not possess WMD but sought to conceal this fact given that it lived among hostile neighbours. Yet it is clear that senior intelligence figures remained wedded to their core assumption. As Scarlett told Chilcot about the situation in January-February 2003, when UNMOVIC were not finding WMDs, 'the reaction might have been: well, why is that? But the reaction was: well it's there. This just goes to show that UNMOVIC aren't much use and we will find it. ${ }^{66}$

\section{Phase Three: Pre-War Intelligence Post-War}

The Chilcot Report shows how, after the 2003 war, the government and intelligence community were reluctant to admit and recognise publicly the mounting evidence that there had been failings in pre-conflict collection, validation, analysis and presentation of intelligence on Iraq's WMD. In essence, the Chilcot Report finds that the intelligence community operated in classic bureaucratic politics terms - that is, in acting to minimise risks to its autonomy, organisational essence, roles and missions, and budgets in light of suboptimal performance. The intelligence held to demonstrate that Iraq continued to develop WMD was widely and loudly disseminated. We noted earlier how Sir Richard Dearlove briefed Tony Blair personally on the 11 September 2002 SIS report the day after it was written. Evidence that this intelligence was mistaken was treated very differently. The Chilcot Report does not explicitly ask this question, but the Report's coverage of this phase begs it: does the intelligence failure over Iraq extend to a failure to be open and acknowledge the extent and nature of the failings once these became known? If one hallmark of good intelligence is timeliness, shouldn't this also be a hallmark of how failure is acknowledged and lessons learned? It was only as a consequence of the Butler review that this kind of institutional learning occurred, but this was an inquiry that the Prime Minister did not want, and that was only conceded as a result of developments in the US.

By mid-February 2003 it was becoming increasingly evident that the source that had passed on the intelligence contained in the 11 and 23 September SIS reports had been lying to

\footnotetext{
${ }^{64}$ Ibid, para 693

65 Ibid, para 716.

${ }^{66}$ Ibid, para 724.
} 
SIS. As a result, SIS arrived at the view that no further material was likely to emerge from the source and that it should attempt to make direct contact with the sub-source. ${ }^{67}$ None of this was communicated to key policy-makers, including the Prime Minister, in the weeks before war began. Moreover, the 11 and 23 September reports continued to enjoy something of a life even after this point. They were sent to John Scarlett on 3 April 2003 by an SIS officer along with an explanatory note. This note said that the reports had not been drawn upon by SIS for the September dossier and that while Sir Richard Dearlove had briefed the Prime Minister on them in September, 'for speed the reports were issued to other readers without a full briefing'. ${ }^{68}$ The note went on to say:

You may therefore wish to know something of the background to the case. The material came from an Iraqi subsource who was working within the CW programme [via SIS source]. We are still endeavouring to establish direct contact with him [the sub-source]; until we succeed in this we shall not be able to verify fully the details given in the intelligence. But despite the later behaviour of our source, we have no reason yet to dismiss this material. There has been collateral for some of it [from other reporting issued on 30 March 2003]. ${ }^{69}$

Seemingly on the same day, a new SIS report was issued that merged the two earlier reports with fresh analysis by SIS. This included the observation that the glass containers described were 'remarkably similar to the fictional chemical weapon portrayed in the film The Rock'; and the admission that this fact had been commented upon by a recipient of the 23 September report. As the Chilcot Report notes, this information 'significantly changed the context in which the details were subsequently presented in the reissued report'. ${ }^{70}$ While this new report went to officials in the Foreign Office and MoD, including DIS, it did not go to the original recipients of the September reports.

It would be June 2003 before SIS finally met the sub-source, only for him to deny that he had provided the information claimed to be from him, leading SIS to conclude that the source was a fabricator 'who had lied from the outset'. ${ }^{71}$ Shortly afterwards, on 3 July, an SIS Requirements Officer (responsible for the quality assurance of source reporting within SIS) wrote that it was necessary to withdraw the reports, advising that: 'Without denying that these reports are no longer valid, we need to ensure their withdrawal does not provide widespread scepticism about our CW reporting, particularly in the absence of a convincing CW find. ${ }^{72}$ When Sir Richard Dearlove appeared before the ISC in mid-July 2003, he informed them of the withdrawal of the intelligence (which was formally withdrawn on 29 July 2003). However, the ISC failed to mention this significant fact in its report on Iraqi WMD intelligence. Notwithstanding his admission to the ISC, in a covering letter accompanying SIS's annual report for 2002-2003, Sir Richard wrote of his confidence 'that the intelligence picture to which we contributed pre-conflict will be proved correct'. ${ }^{73} \mathrm{He}$ also noted that

We risk damage to the credibility of the intelligence community if the public perception remains that our intelligence may have been wrong. If we can persuade Iraqi scientists involved in the programme to go public, then we may be able to turn the media debate more in our favour and reduce our dependence on the eventual outcome of the physical search. ${ }^{74}$

\footnotetext{
${ }^{67}$ Ibid, para 515.

${ }^{68}$ Ibid, para 523.

${ }^{69}$ Ibid, para 524

${ }^{70}$ Ibid, para 527.

${ }^{71}$ Ibid, para 532.

72 Ibid, para 534.

${ }^{73}$ Ibid, para 542.

${ }^{74}$ Ibid, para 543.
} 
Despite the ISC having been informed of the withdrawal of these reports (although it treated this information as a secret), the Prime Minister, Foreign Secretary and Defence Secretary seem not to have been informed. Jack Straw said he only became aware of the withdrawal in September 2003 when SIS requested that the reports be released to the ISC, and Blair even later as a result of the Butler review. The Chilcot Report noted that the "very low key manner' in which the reporting was withdrawn contrasted with the way in which it was originally issued, ${ }^{75}$ and was critical of Dearlove's part in this:

Given the controversy about the failure to find WMD and questions about whether the intelligence had been presented accurately after the conflict, Sir Richard Dearlove should have ensured that Ministers were aware of the position when he informed the Intelligence and Security Committee that the intelligence had been withdrawn. ${ }^{76}$

In his evidence to the ISC, Dearlove had reassured them that the intelligence reporting underpinning the eye-catching claim in the September 2002 dossier that Iraq could launch chemical or biological weapons within 45 minutes of an order to do so was 'reliable'. ${ }^{77}$ However, in June 2004 SIS informed the Foreign Office and Downing Street that there were concerns relating to the reporting chain responsible for this, 'casting doubt on the reliability of information' it had provided. ${ }^{78}$ On seeing the relevant papers, the Foreign Secretary asked them to be passed to 10 Downing Street immediately, 'commenting that SIS's description of the new information as a "snag" was "a very major understatement", and that the information seemed "to drive a coach and horses through the veracity of the 45 -minute claim". ${ }^{79}$ The sub-source responsible for this claim had been the basis for five SIS reports that fed into JIC Assessments in August, September, October, December 2002 and February 2003. Hence, even if, as was claimed, the specific intelligence was not crucial to key judgements, it had nevertheless reinforced the high levels of confidence that intelligence had a good understanding of Iraq's WMD aims and strategy. However, the source had been crucial to the '45 minutes' claim. ${ }^{80}$ On 28 September 2004 the reporting from this sourcing chain was formally withdrawn. As the Chilcot Report puts it: 'There were concerns that the source had coached the sub-source; that the sub-source had fabricated reports; and that the source might not have accurately reported the information from the sub-source. ${ }^{81}$ Chilcot identifies the reason behind the low-key manner in which the withdrawals occurred, albeit with a degree of understatement. As the WMD that had constituted the case for war failed to turn up in 2003 and 2004, the 'Government and intelligence community were both concerned about the consequences of the presentational aspects of their pre-war assessments being discredited.' ${ }^{82}$

\section{CONCLUSIONS: The CHILCOT INQUIRY AND THE NATURE OF THE IRAQ WMD INTELLIGENCE FAILURE}

The Chilcot Report adds considerable depth to our understanding of the intelligence failure in this case, providing the sense of perspective necessary to see it extending across three distinct phases. The report's analysis regarding WMD intelligence in phase one is consistent with that

\footnotetext{
75 Ibid, para 565.

76 Ibid, para 585.

77 Ibid, para 588.

${ }^{78}$ Ibid, para 589.

${ }^{79}$ Ibid, para 592.

${ }^{80}$ Ibid, paras 604-6.

${ }^{81}$ Ibid, para 628.

${ }^{82}$ Report, vol 4, Section 4.4, para 911.
} 
provided by the earlier Butler Report, which it regularly cites, but is more detailed. The Chilcot Report's narrative gives the sense that the failure in phase two was at least as significant as that which occurred in the earlier phase. The phase three dimension is something that no previous inquiry could capture, and only emerges from the Chilcot Report. The evidence to the Chilcot Inquiry also indicates that the failure in this case was neither mono-causal nor capable of being diagnosed as either intelligence or policy failure. Each of the approaches to thinking about intelligence failure discussed in Part II above has some relevance to this case. For example, it is possible to identify failures as occurring at each stage of the intelligence cycle and to seek to attach relative to weight to these. It is possible to focus on the intelligence-consumer interface, as Richard Betts directs us to do. One can see varieties of politicization at work. Structural and bureaucratic politics explanations also have some applicablity to the unfolding of events. However, the Chilcot Report allows the reader to see that the failure in this case was the product of a mutually reinforcing politicointelligence dynamic that developed in an environment created by policy choices. In this sense, it may be considered an expression of politicization, but a focus on 'politicization' alone fails to capture the mutually-reinforcing dynamic that was necessary to this failure. Intelligence participation in the September 2002 dossier and the certainty with which the case against Iraq was presented played a key role in locking intelligence in-step with government. The part played by intelligence served to reinforce government confidence in the reliability of existing beliefs and neutralised existing and potential political opposition, whether in Cabinet or Parliament. If such close involvement in the dossier project was an error, that there was no review of intelligence judgements from September 2002 until war broke out was a clear, and distinct, failure. Faced with an absence of evidence that WMD existed, intelligence persisted in the belief that this was a consequence of clever Iraqi denial and deception practices rather than revisit core assumptions. This was the lesson intelligence drew from past Iraqi behaviour. Consequently, it was reluctant to accept absence of evidence as evidence of absence. To reiterate, the environment in which this occurred was one created by politicians. If the case against Iraq had been as clear as politicians claimed throughout 2002 there would have been no need to seek out fresh and damning intelligence at the eleventh hour to make the September dossier fit for purpose. It would already have existed. Similarly, there would have been no need to seek 'silver bullet' intelligence to direct the UNMOVIC inspection regime in late 2002-early 2003. The compelling evidence for all of this would have existed before politicians began making the public case in increasingly strident terms throughout the course of 2002. Instead, intelligence was drawn into proving a case that had already been set out by politicians but not substantiated by clear evidence, compromising best practice standards in the process and leading to a disaster. After March 2003 intelligence found itself somewhere between playing-down and covering-up the scale of its failures, essentially for reasons rooted in bureaucratic politics.

How far is intelligence failure avoidable and how far are the lessons to be learned from the Chilcot Report likely to minimise the risk of future failure? Definitive answers to these questions are impossible, but some observations can be offered with a degree of confidence. On the one hand, the Iraq WMD episode is the most intensively-investigated instance of intelligence failure in history, with several major inquiries having taken place in the UK, US and Australia. As a result, we now know more about the dynamics of intelligence failure than ever before. Lessons have been learned and organisational reforms aimed at minimising the risk of a recurrence implemented. Understanding the bases and complexity of intelligence failure are important first steps in guarding against it. On the other hand, intelligence history shows that the clarity of lessons from the past is no guarantee that future failure will be avoided. 
One important lesson that does emerge is the need for improved executive, legislative and public understanding of the role and limits of intelligence. In this case, the Blair government's public use of intelligence in selling the war option functioned as an obstacle to such an understanding. As Lord Butler argued in the House of Lords debate on the Chilcot Report: "As countless examples from history show, intelligence is not uniquely worthy of belief: it is uniquely worthy of scepticism. However, this should not lead us to the conclusion that intelligence is valueless or stop us investing in it. In today's world, intelligence is crucial ... We need to learn the lesson that intelligence is a very valuable - indeed, indispensableaid to political and military judgment, but it is not a determinant. ${ }^{83}$

It must be doubtful whether in future there will ever be another governmental exercise along the lines of the September 2002 dossier, drawing selectively on secret intelligence to sell policy. There would be no political or professional intelligence appetite for it. In any case, neither public nor Parliament would be likely to greet any such exercise with anything except suspicion. In part, the lack of professional appetite would reflect a recognition that intelligence was drawn too closely into advocacy in this case. This denied it the possibility of critical distance thereafter. Hence, one valid interpretation of Chilcot's evidence on Iraq WMD intelligence is that 'spy chiefs were too eager to please, ${ }^{, 84}$ reflecting the mutually reinforcing politico-intelligence dynamic and pointing us back to the importance of the nature of the environment in which intelligence work is conducted. As Sir John Chilcot told the House of Commons Liaison Committee: 'Exaggeration-placing more weight on the intelligence than it could possibly bear-is a conclusion that we reached on the Butler committee and reached again with even more evidence in the Iraq inquiry. ${ }^{85}$ As Chilcot also makes clear, this was a shared politico-intelligence failure.

\footnotetext{
${ }^{83}$ HL Deb 12 July 2016, vol 774, col 136.

84 'Spy chiefs were too eager to please with flawed weapons intelligence', The Times (7 July 2016) 14.

${ }^{85}$ House of Commons Liaison Committee, 'Oral Evidence: Follow up to the Chilcot Report', 2 November 2016 (HC 689) <https://www.parliament.uk/documents/commons-committees/liaison/John-Chilcot-oralevidence.pdf $>$, Q.128.
} 